\title{
Analysis of PET parameters as prognosticators of survival and tumor extent in Oropharyngeal Cancer treated with surgery and postoperative radiotherapy
}

Kyu Hye Choi ${ }^{1}$, Jin Ho Song ${ }^{1}$, Eun Young Park', Ji Hyun Hong ${ }^{1}$, le Ryung Yoo ${ }^{2}$, Youn Soo Lee ${ }^{3}$, Dong-II Sun ${ }^{4}$, Min-Sik Kim ${ }^{4}$ and Yeon-Sil Kim ${ }^{1 *}$

\begin{abstract}
Background: Positron-emission tomography (PET) is widely used to detect malignancies, but consensus on its prognostic value in oropharyngeal cancer has not been established. The purpose of this study was to analyze the PET parameters associated with tumor extent and survival in resectable oropharyngeal cancer.

Methods: The PET parameters in oropharyngeal cancer patients with regional node metastasis who underwent surgery and postoperative radiotherapy between January 2005 and January 2019 were analyzed. We calculated the SUVmax, tumor-to-liver ratio (TLR), metabolic tumor volume (MTV, volume over SUV 2.5), and total lesion glycolysis (TLG, MTV x mean SUV) of the primary lesion and metastatic nodes. Histologic findings, patient survival, and recurrence were reviewed in the medical records.
\end{abstract}

Results: Fifty patients were included, and the PET parameters were extracted for 50 primary lesions and 104 nodal lesions. In the survival analysis, MTV and TLG of the primary lesions showed significant differences in overall survival (OS) and recurrence-free survival (RFS). In the multiple regression analysis, TLG of the primary lesion was associated with the depth of invasion (DOI). MTV of the nodes was a significant factor affecting extranodal extension (ENE).

Conclusions: PET parameters could be related with OS, RFS, DOI of the primary tumor, and ENE. PET would be expected to be a useful diagnostic tool as a prognosticator of survival and pathologic findings in oropharyngeal cancer.

Keywords: Oropharyngeal cancer, PET, SUVmax, Depth of invasion, Extranodal extension

\footnotetext{
* Correspondence: yeonkim7@catholic.ac.kr

'Department of Radiation Oncology, Seoul St. Mary's Hospital, College of

Medicine, The Catholic University of Korea, Seoul, Republic of Korea

Full list of author information is available at the end of the article
}

(c) The Author(s). 2021 Open Access This article is licensed under a Creative Commons Attribution 4.0 International License, which permits use, sharing, adaptation, distribution and reproduction in any medium or format, as long as you give appropriate credit to the original author(s) and the source, provide a link to the Creative Commons licence, and indicate if changes were made. The images or other third party material in this article are included in the article's Creative Commons licence, unless indicated otherwise in a credit line to the material. If material is not included in the article's Creative Commons licence and your intended use is not permitted by statutory regulation or exceeds the permitted use, you will need to obtain permission directly from the copyright holder. To view a copy of this licence, visit http://creativecommons.org/licenses/by/4.0/ The Creative Commons Public Domain Dedication waiver (http://creativecommons.org/publicdomain/zero/1.0/) applies to the data made available in this article, unless otherwise stated in a credit line to the data. 


\section{Background}

With the development of functional imaging, positronemission tomography (PET) has been used as a diagnostic method by tracking metabolic activity with radioactive isotopes that emit positrons [1].The most commonly used ${ }^{18} \mathrm{~F}$-fluorodeoxyglucose $\left({ }^{18} \mathrm{~F}\right.$-FDG) radioactive isotope is a glucose-like substance, which shows active glucose metabolism in lesions such as cancer, and it can be a useful tool for detecting cancer spread in the body. By combining PET-scanning with computed tomography (CT), anatomical information and accurate image correction can be achieved [2].

PET provides objective and reproducible information through standardized uptake values (SUV), from which a quantitative factor is extracted, and the maximum SUV is known to be related to survival rate in several solid tumors [3-5]. Previous studies on the association between PET parameters and prognosis have been actively conducted, but consensus has not established the application of PET as a staging tool or its prognostic value in solid tumors [6-8]. PET is usually used as supplementary anatomic imaging for assessing tumors or nodal extension in clinical settings.

In head and neck cancer, the nodal stage is based on several studies in which the extranodal extension (ENE) of the lymph nodes (LNs) affected the prognosis [9-11]. It is also known that the depth of invasion (DOI) of the primary tumors is an important prognostic factor associated with local recurrence [12,13]. The expression of human papillomavirus (HPV) has recently been studied as a factor affecting the prognosis of patients with oropharyngeal cancer, and different staging systems have been established according to HPV status $[14,15]$. The purpose of this study was to analyze the association between surgical histologic findings of oropharyngeal cancer and PET parameters before treatment and assess their prognostic role in survival and pathology.

\section{Methods}

\section{Patient population}

This was a retrospective study conducted on patients who were diagnosed with resectable oropharyngeal cancer and underwent surgery from January 2005 to January 2019. The resectability was based on the technical ability to clear margins and the possibility of total cancer removal in primary site and involved LNs. The eligibility criteria were: 1 ) primary tumor stage $\mathrm{T} 1-4$ and regional node metastasis without distant metastasis at initial diagnosis; 2) squamous cell carcinoma confirmed through biopsy; 3) PET-CT examination before treatment; 4) patients who underwent curative resection with LN dissection and completed adjuvant chemoradiotherapy or radiotherapy as needed; and 5) patients with Karnofsky scores $\geq 70$ and ages of 19-70 years. Patients who underwent neoadjuvant chemotherapy before surgery were excluded. Primary tumor resection was conducted with wide excision in an effort to obtain enough surgical margin. Modified radical neck dissection was done for the clinically positive cervical nodes, and selective neck dissection was done as an elective neck treatment on the clinically negative neck node region. The indications and modalities for adjuvant (chemo)radiotherapy were cases of positive or close margins found on the resection, multiple lymph-node metastasis, extranodal extension of involved LNs, advanced $\mathrm{T}$ classification, lymphovascular invasion, and perineural invasion requiring additional treatment.

This study was conducted in accordance with the Declaration of Helsinki. The Institutional Review Board of the Catholic Medical Center, the Catholic University of Korea approved the study protocol (No. KC19RISI0812). Informed consent was waived due to the retrospective study design by the same ethics committee that approved this study (The Institutional Review Board of the Catholic Medical Center, the Catholic University of Korea).

\section{Treatment technique and ${ }^{18} \mathrm{~F}$-FDG PET-CT protocol}

All patients fasted for $\geq 6 \mathrm{~h}$ before the PET-CT scans and were in the supine position during scanning. There were no patients with blood glucose levels above $150 \mathrm{mg} / \mathrm{dL}$ before injection. The intravenous injection of 3.7-5.5 $\mathrm{MBq} / \mathrm{kg}$ of ${ }^{18} \mathrm{~F}$-FDG started the scan $60 \mathrm{~min}$ later. Intravenous contrast agent was not administered and images were acquired using a combined PET-CT in-line system with a Biograph Duo or Biograph TruePoint (Siemens Medical Solutions, Knoxville, TN, USA) and a Discovery 710 (GE Healthcare, Milwaukee, WI, USA).

\section{Target volume delineation and imaging analysis}

SUV was calculated using a standard calibration for body weight and injection dose. The primary tumor and metastatic nodes were identified in the region-of-interest (ROI). The maximum SUV (SUVmax), metabolic tumor volume (MTV), and total lesion glycolysis (TLG) were extracted from the analysis of the PET parameters. The primary tumor was delineated using CT and the metastatic nodes more than $1 \mathrm{~cm}$ in longest diameter with a minimal SUVmax of 1.5 were included in analysis. Correction by mean SUV of liver was used to compute the ratio of the tumor-to-liver SUV (TLR) to compensate for the difference due to the three different scanners $[16$, 17]. For mean SUV of liver, three non-overlapping spherical volumes of interest (VOIs) with a diameter of $3 \mathrm{~cm}$ in the liver (2 in the right lobe and 1 in the left lobe) were drawn and the average value was calculated. The MTV was defined by an SUV volume of $\geq 2.5$ in the ROI and the TLG was calculated as MTV $\mathrm{x}$ mean SUV. MIM software version 6.8.3 (MIM Software Inc., 
Cleveland, OH, USA) was used to extract these parameters, and each volume was determined within the ROI by the review software.

\section{Statistical analysis}

The surgical pathology reports of the patients were reviewed to determine the DOI of the primary tumor, the ENE of metastatic nodes, and other important pathologic findings in oropharyngeal cancer. A receiver operating characteristic (ROC) curve was used to evaluate the prognostic power of volumetric factor for recurrence and Pearson's correlation coefficients were calculated to evaluate the relationship between PET parameters and the pathologic findings. Overall survival (OS) was defined as the time from the date of curative surgery to death and recurrence-free survival (RFS) was defined as the time from the date of curative surgery until the first evidence of disease recurrence. Subsequent follow-up for death and recurrence were recorded, and the OS and RFS were evaluated using Kaplan-Meier curves and the log-rank test. Univariate and multivariate regression models with logistic regression analyses were performed to analyze the factors associated with surgical pathologic findings. The statistical analyses were conducted using SPSS software version 24 (IBM, Armonk, NY, USA).

\section{Results}

\section{Patient and PET parameters characteristics}

During the study period, 252 patients with oropharyngeal cancer were treated at Seoul St. Mary's Hospital. Of these, 74 patients underwent PET-CT before treatment and a total of 50 patients, except for 24 patients who underwent neoadjuvant chemotherapy, were included in the study. The PET parameters were extracted for 50 primary lesions and 104 nodal lesions. Among the 104 nodes, 38 were ENE-positive nodes, 47 were negative, and the ENE status was unavailable on 19 nodes. The range of the values in the primary tumors $(\mathrm{T})$ was 4.49 28.7 (median, 9.92) for T-SUVmax, 2.07-13.41 (median, 4.57) for T-TLR, 2.65-64.62 $\mathrm{cm}^{3}$ (median, $10.89 \mathrm{~cm}^{3}$ ) for T-MTV, and $8.63-619.51 \mathrm{~cm}^{3}$ (median, $40.29 \mathrm{~cm}^{3}$ ) for T-TLG. There was no difference in mean SUV values of liver between the high and low TLR groups. The range of the variables for each of the 104 metastatic nodes $(\mathrm{N})$ was calculated as follows: N-SUVmax, 2.66-19.86 (median, 6.71); N-TLR, 1.10-8.84 (median, 3.07); N-MTV, $0.05-133.87 \mathrm{~cm}^{3}$ (median, $2.90 \mathrm{~cm}^{3}$ ); and N-TLG, 0.13$904.41 \mathrm{~cm}^{3}$ (median, $10.18 \mathrm{~cm}^{3}$ ). To evaluate the metastatic nodal burden of each patient, the parameters of the total metastatic nodes were further analyzed. For the total metastatic nodes $(\mathrm{tN})$ in the patients, the median tN-SUVmax was 8.13 (range, 2.95-19.86), the median $\mathrm{tN}-\mathrm{TLR}$ was 3.53 (range, 1.10-8.84), the median $\mathrm{tN}$ -
MTV was $10.38 \mathrm{~cm}^{3}$ (range, $0.25-133.87 \mathrm{~cm}^{3}$ ), and the median tN-TLG was $39.69 \mathrm{~cm}^{3}$ (range, $0.72-904.41$ $\mathrm{cm}^{3}$ ). The patient, treatment, and tumor characteristics are listed in Table 1.

\section{Volumetric parameters and survival}

In the median 90.75 months of follow-up, there were eight (16\%) recurrences and $12(24 \%)$ deaths. A ROC curve was used to evaluate the prognostic power of $\mathrm{T}$ MTV and T-TLG for recurrence (Fig. 1). The area under the curve (AUC) showed fair prognostic power of 0.824 and 0.807 for T-MTV and T-TLG, respectively (T-MTV: $P=0.004,95 \%$ confidence interval (CI): 0.636-1.000; TTLG: $P=0.006,95 \%$ CI: $0.613-1.000)$. After ROC curve generation, OS and RFS were analyzed by dividing TMTV $15 \mathrm{~cm}^{3}$ and T-TLG $70 \mathrm{~cm}^{3}$ by their cutoff values with high sensitivity and specificity. The analysis of OS and RFS for T-MTV showed significant differences between the T-MTV $\leq 15 \mathrm{~cm}^{3}$ and $>15 \mathrm{~cm}^{3}$ groups (OS, $P=0.013$; RFS, $P=0.003$ ). The survival analysis for $\mathrm{T}$ TLG showed significant differences in RFS $(P=0.018)$ and marginally significant differences in OS $(P=0.058)$ between the T-TLG $\leq 70 \mathrm{~cm}^{3}$ and $>70 \mathrm{~cm}^{3}$ groups. Figure 2 shows the Kaplan-Meier curves of OS and RFS for T-MTV and T-TLG.

Survival analysis based on metastatic nodes was performed by setting the cutoff values for tN-MTV to 10 $\mathrm{cm}^{3}$ and $\mathrm{tN}-\mathrm{TLG}$ to $35 \mathrm{~cm}^{3}$, which showed high sensitivity and specificity in the ROC curves for recurrence. There was no significant difference between tN-MTV and $\mathrm{tN}$-TLG in the log-rank test for OS $(P=0.272$ in tN-MTV, 0.088 in tN-TLG). Survival analysis for RFS showed no significant difference in tN-MTV $(P=$ $0.136)$, whereas it showed significant difference in $\mathrm{tN}$ TLG $(P=0.039)$.

In summary, the T-MTV and T-TLG of primary tumors were statistically significant prognostic factors for OS and RFS. Among the metabolic parameters of metastatic LNs, tN-TLG also showed prognostic power.

\section{PET parameters and pathology of the primary tumors}

The relationship between T-MTV and T-TLG and the DOI of the primary tumor is shown in Fig. 3. Pearson's correlation coefficients were 0.815 for T-MTV and 0.751 for T-TLG $(P<0.001$, both), representing good correlation. ROC analysis was performed for determining the cutoff points. The AUC of T-MTV and T-TLG were 0.836 (95\% CI: 0.712-0.957) and 0.834 (95\% CI: 0.7150.958 ), respectively, demonstrating fair prognostic value for deep invasive tumors (DOI $>10 \mathrm{~mm}$ ) (Fig. 4a). TMTV above $10 \mathrm{~cm}^{3}$ and high T-TLG above $45 \mathrm{~cm}^{3}$ were cutoff points with high sensitivity and specificity for DOI. Logistic regression (Table 2A) analysis was performed to correlate the DOI with metabolic parameters 
Table 1 Patient, treatment (A), and tumor (B) characteristics $(N=50)$

\begin{tabular}{|c|c|}
\hline Characteristic & $\begin{array}{l}\mathrm{N}(\%) \text { or } \\
\text { median (range) }\end{array}$ \\
\hline \multicolumn{2}{|l|}{ (A) } \\
\hline \multicolumn{2}{|l|}{ Patient characteristics } \\
\hline Age & $59(29-75)$ \\
\hline \multicolumn{2}{|l|}{ Primary site } \\
\hline Tonsil & $41(82)$ \\
\hline Base of tongue & $7(14)$ \\
\hline Soft palate & $2(4)$ \\
\hline \multicolumn{2}{|l|}{ Sex } \\
\hline Male & $45(90)$ \\
\hline Female & $5(10)$ \\
\hline \multicolumn{2}{|l|}{ Smoking history } \\
\hline Non-smoker & $17(34)$ \\
\hline Smoker $\leq 10$ PPY & $5(10)$ \\
\hline Smoker $>10$ PPY & $28(56)$ \\
\hline \multicolumn{2}{|l|}{ Treatment characteristics } \\
\hline \multicolumn{2}{|l|}{ Primary surgery } \\
\hline Wide excision & $26(52)$ \\
\hline Transoral robotic surgery & $24(48)$ \\
\hline \multicolumn{2}{|l|}{ Ipsilateral neck dissection } \\
\hline Radical neck dissection & $4(8)$ \\
\hline Modified radical neck dissection & $46(92)$ \\
\hline \multicolumn{2}{|l|}{ Contralateral neck dissection } \\
\hline Modified radical neck dissection & $4(8)$ \\
\hline Selective neck dissection & $37(74)$ \\
\hline Not-done & $9(18)$ \\
\hline \multicolumn{2}{|l|}{ Adjuvant treatment } \\
\hline Chemoradiotherapy & $35(70)$ \\
\hline Radiotherapy & $15(30)$ \\
\hline \multicolumn{2}{|l|}{ (B) } \\
\hline \multicolumn{2}{|l|}{ T stage } \\
\hline $\mathrm{T} 1$ & $24(48)$ \\
\hline $\mathrm{T} 2$ & $24(48)$ \\
\hline T3-T4 & $2(4)$ \\
\hline Depth of invasion (mm) & $9(7-37)$ \\
\hline \multicolumn{2}{|l|}{ LN number } \\
\hline $1-4$ & $36(72)$ \\
\hline$>4$ & $14(28)$ \\
\hline \multicolumn{2}{|l|}{ Largest LN size $(\mathrm{cm})$} \\
\hline$\leq 3$ & $26(52)$ \\
\hline$>3$ but $\leq 6$ & $19(38)$ \\
\hline$>6$ & $1(2)$ \\
\hline N/A & $4(8)$ \\
\hline
\end{tabular}

Table 1 Patient, treatment (A), and tumor (B) characteristics $(N=50)$ (Continued)

\begin{tabular}{ll}
\hline Characteristic & $\begin{array}{l}\text { N (\%) or } \\
\text { median (range) }\end{array}$ \\
\hline Extranodal extension & $21(42)$ \\
Negative & $29(58)$ \\
Positive & \\
Tumor grade & $30(60)$ \\
Well to moderately & $16(32)$ \\
Poorly & $4(8)$ \\
N/A & \\
HPV status & $18(36)$ \\
Negative & $27(54)$ \\
Positive & $5(10)$ \\
N/A & \\
Surgical margin & $35(70)$ \\
Negative & $15(30)$ \\
Positive or close & \\
Lymphatic invasion & $29(58)$ \\
Yes & $21(42)$ \\
No & \\
Vascular invasion & $4(10)$ \\
Yes & $46(92)$ \\
No & \\
Yerineural invasion & \\
No & \\
\hline
\end{tabular}

Abbreviation: $P P Y$ packs per year, $L N$ lymph node, N/A not-available, HPV human papilloma virus

of the primary tumor and other pathologic factors. TMTV and T-TLG showed statistically significant differences in univariate analysis for DOI $>10 \mathrm{~mm}$ (MTV, $P=$ 0.003; TLG, $P<0.001)$. T-TLG was also analyzed in multivariate analysis as a significant associated factor $(P<0.001$; odds ratio $=13.143$; 95\% CI: 3.292-52.466 $)$. However, neither any other PET parameters, the HPV status, nor histologic variables, such as adjacent structure involvement, lymphovascular or perineural invasion, were associated with the DOI.

\section{PET parameters and extranodal extension}

The PET parameters were analyzed for 85 nodes to determine whether they matched well-known pathological variables of ENE. ROC curves were generated in the analysis of the prognostic value of N-MTV and N-TLG for ENE. The AUCs were 0.630 (95\% CI: 0.509-0.751) and 0.631 (95\% CI: 0.510-0.753), respectively, (Fig. 4b) and cutoff values of $4 \mathrm{~cm}^{3}$ for tN-MTV and $15 \mathrm{~cm}^{3}$ for tNTLG were obtained (N-MTV: sensitivity $=59 \%$, specificity $=67 \%$; N-TLG: sensitivity $=54 \%$, specificity $=64 \%$ ). 


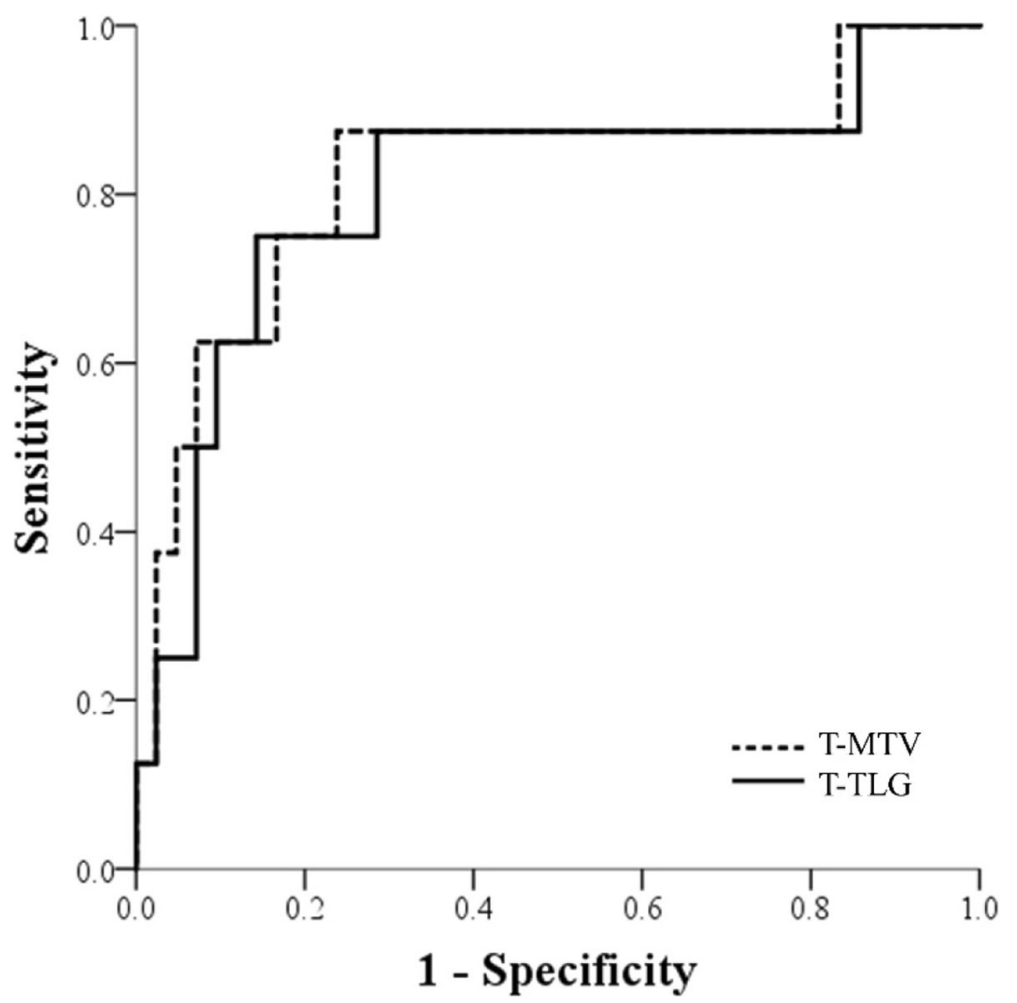

Fig. 1 Receiver operating characteristic curve for recurrence in T-MTV and T-TLG. T-MTV = metabolic tumor volume of primary tumor, T-TLG= total lesion glycolysis of primary tumor

In the evaluation of ENE with PET parameters and pathologic variables, the univariate logistic regression analysis showed that N-SUVmax $(P=0.021)$ and N-MTV $(P=$ $0.018)$ were statistically significantly associated with ENE. And among them, N-MTV was significantly different in multivariate analysis for $\operatorname{ENE}(P=0.016$; odds ratio $=$ 2.933; 95\% CI: 1.205-7.138). The logistic regression analyses of ENE are summarized in Table 2B. In summary, N-MTV could be a useful parameter for the pathologic invasiveness of metastatic nodes.

\section{Discussion}

In head and neck cancer, evaluating the patient's prognosis and disease extent through PET images before surgery can reduce complications related to surgery and increase the cure rate [18]. Prior to this, some studies on the prognostic value of PET parameters have been reported $[19,20]$. Our data have several meaningful perspectives, including the study design that analyzed PET variables in the preoperative staging process for resectable oropharyngeal cancer, and additionally evaluated the association with surgical pathologic findings.

In previous retrospective studies of SUV factors as prognosticators of head and neck cancer patients, the MTV or TLG of the primary tumors and metastatic lymph nodes were determined to be strong prognostic factors [20-23]. Most of them included various subsites of the head and neck and patients treated with induction chemotherapy or definitive chemoradiation therapy in locally advanced-stage cancer. We particularly analyzed PET parameters associated with surgical pathology and survival in patients with oropharyngeal cancer who underwent surgery without neoadjuvant treatment. Since this study was designed for patients undergoing surgery and postoperative radiotherapy, it was possible to simultaneously confirm the clinical results after surgery and radiotherapy, and analyze the ability of pathologic parameters to related with OS and RFS using PET parameters in these homogeneously treated patients. In addition, by excluding patients who were treated with neoadjuvant treatment, variables related to neoadjuvant treatment could be excluded in analyzing the association of pathological findings with PET before surgery.

In this study, SUVmax, MTV, and TLG were analyzed as PET parameters for 50 patients with primary lesions and 104 metastatic lymph nodes. SUVmax, which is widely used, shows only the most active point in a tumor and there is a limit in representing tumor heterogeneity or size. TLR, which supplemented the tumor's SUV value with reference to liver activity, tried to overcome the heterogeneity of the other three PET-CT scanners in our study. Complementing this, MTV, which is a 


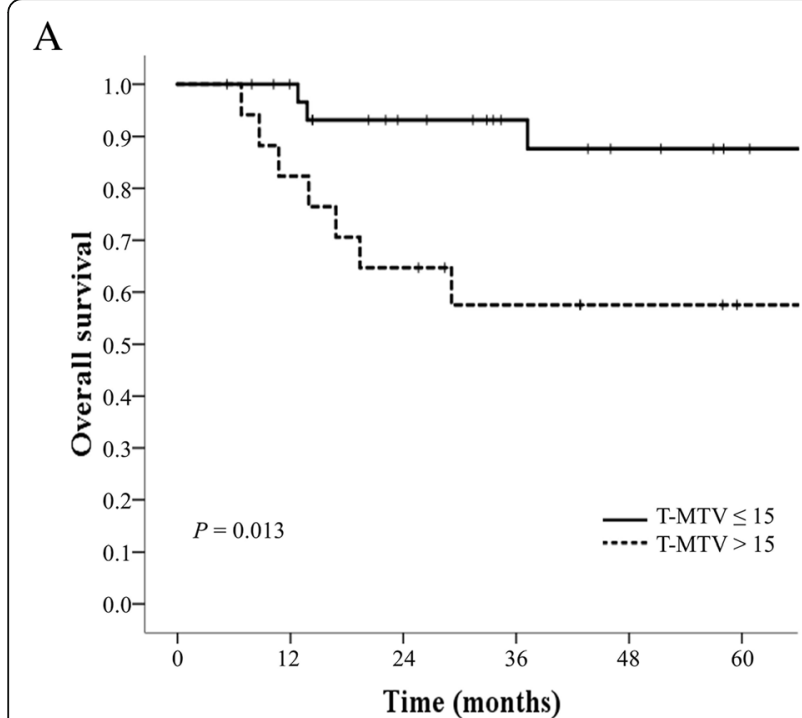

B

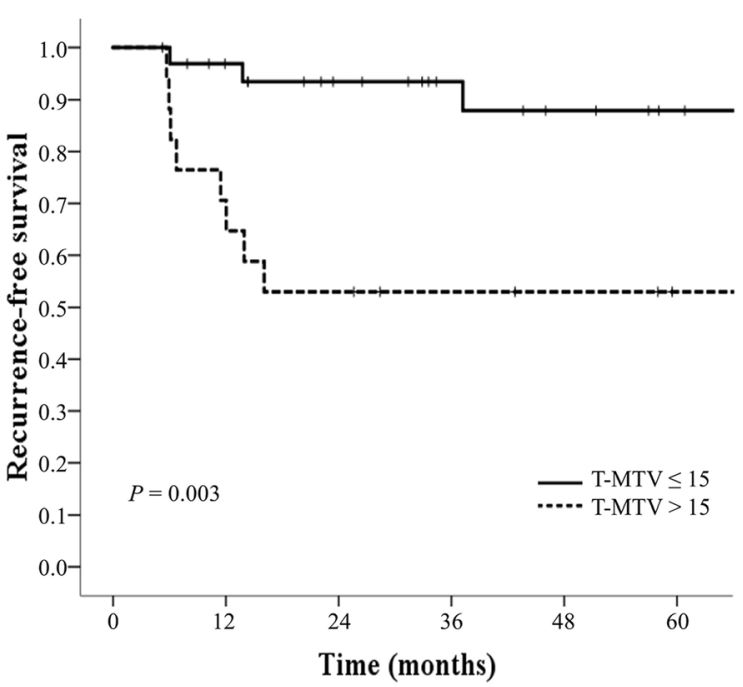

$\mathrm{C}$

$\mathrm{D}$
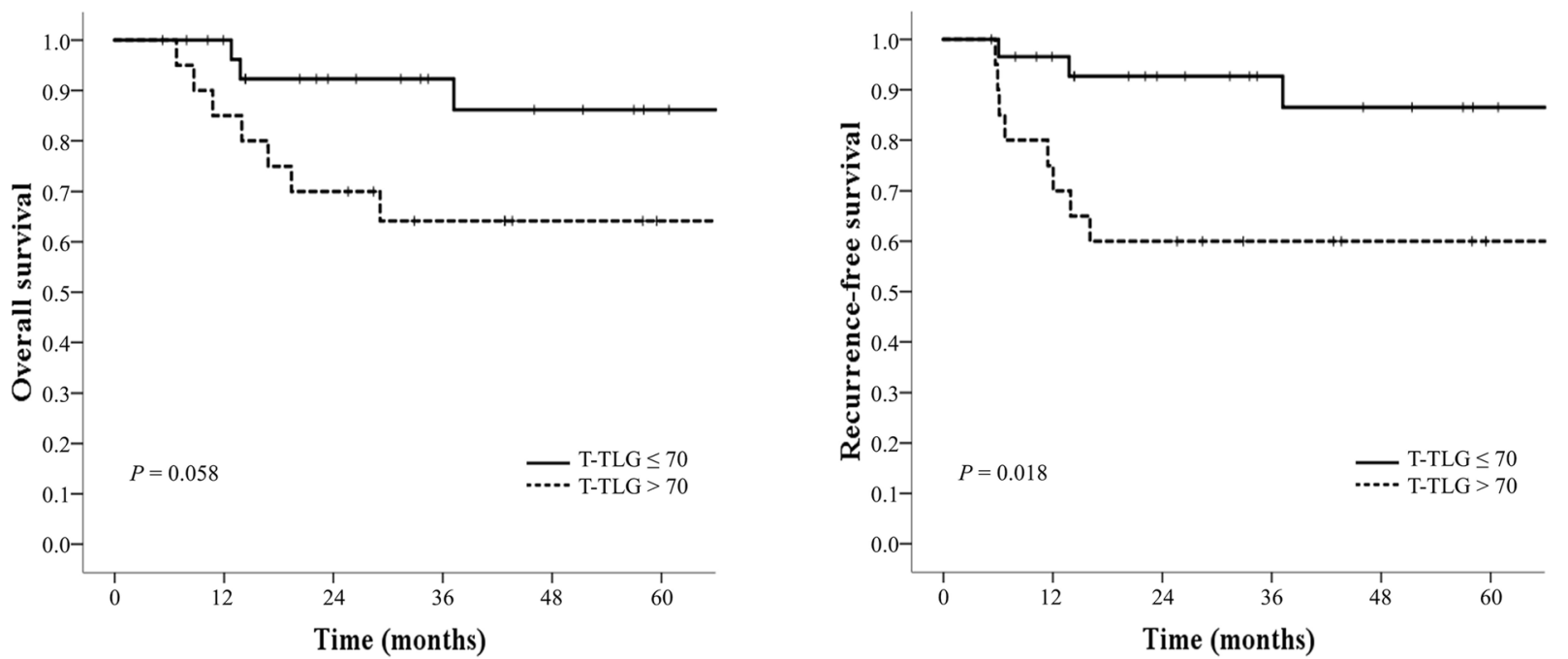

Fig. 2 Survival curves of OS and RFS according to T-MTV $(\mathbf{a}, \mathbf{b})$ and T-TLG $(\mathbf{c}, \mathbf{d})$. OS = overall survival, RFS = recurrence-free survival, T-MTV= metabolic tumor volume of primary tumor, T-TLG = total lesion glycolysis of primary tumor

volume-based parameter, represents an area with a value above a certain SUV, and TLG represents tumor burden by multiplying MTV by mean SUV.

The volume-based parameters of the primary tumors were analyzed as prognosticators of survival and recurrence. Alluri et al. [24] reported that primary tumor MTV was a significant prognostic marker for event-free survival in multivariate analysis in stage III-IV HPVpositive oropharyngeal cancer patients treated with local or systemic treatment. The aim of the current study was to suggest the meaning of PET parameters in resectable oropharyngeal cancer patients with relatively non-bulky regional metastasis. The results showed that volumebased parameters of the primary tumor, such as MTV and TLG, were associated with OS and RFS. The volume-based parameters of the metastatic nodes did not show significant differences in OS or RFS, unlike those of the primary lesions. However, our study should be understood taking into account the inherent biases of the retrospective study design. Because of the limitation of small numbers of patients, metastatic lymph nodes also showed differences in survival in the survival curve, which need to be verified by further large-scale studies.

This study interestingly examined the association between surgical pathology and PET parameters. Previous research has been conducted on the accuracy of MRI in assessing DOI in oral and oropharyngeal cancers [25]. The studies showed that MRI was not clearly associated with the invasion depth of tonsillar cancer. However, in the current study, the volume-based parameters of PET 
A

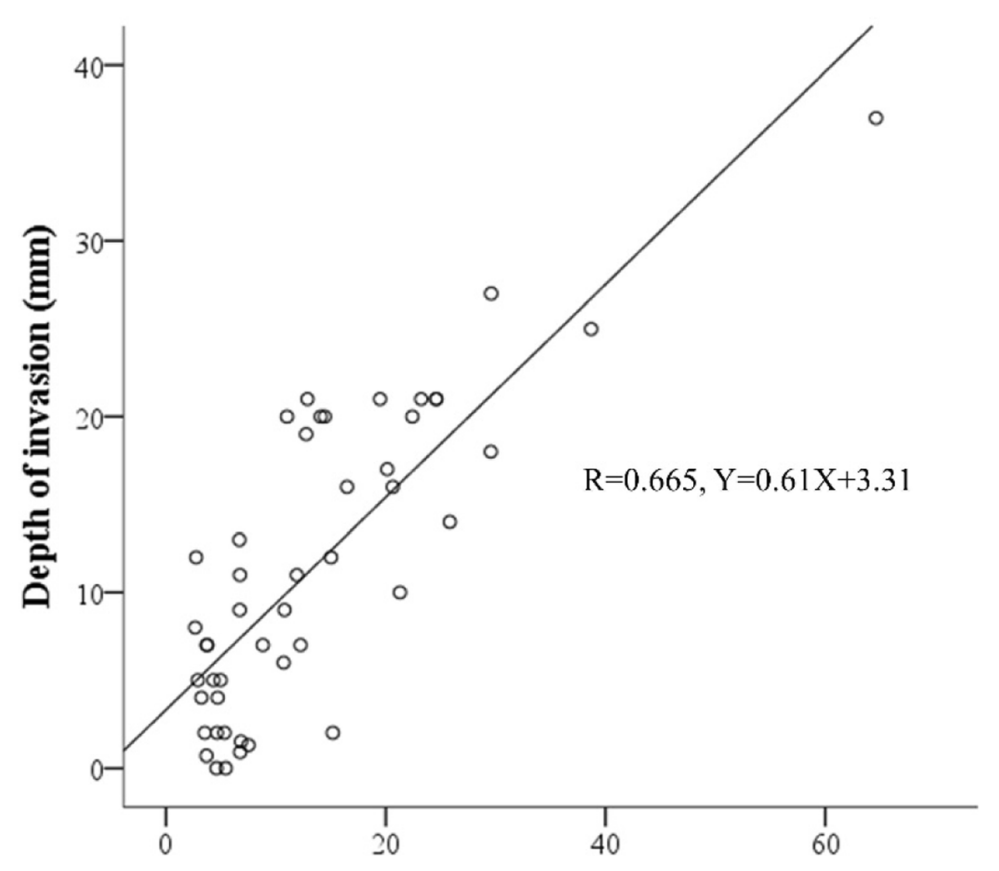

Metabolic tumor volume of primary tumor

B

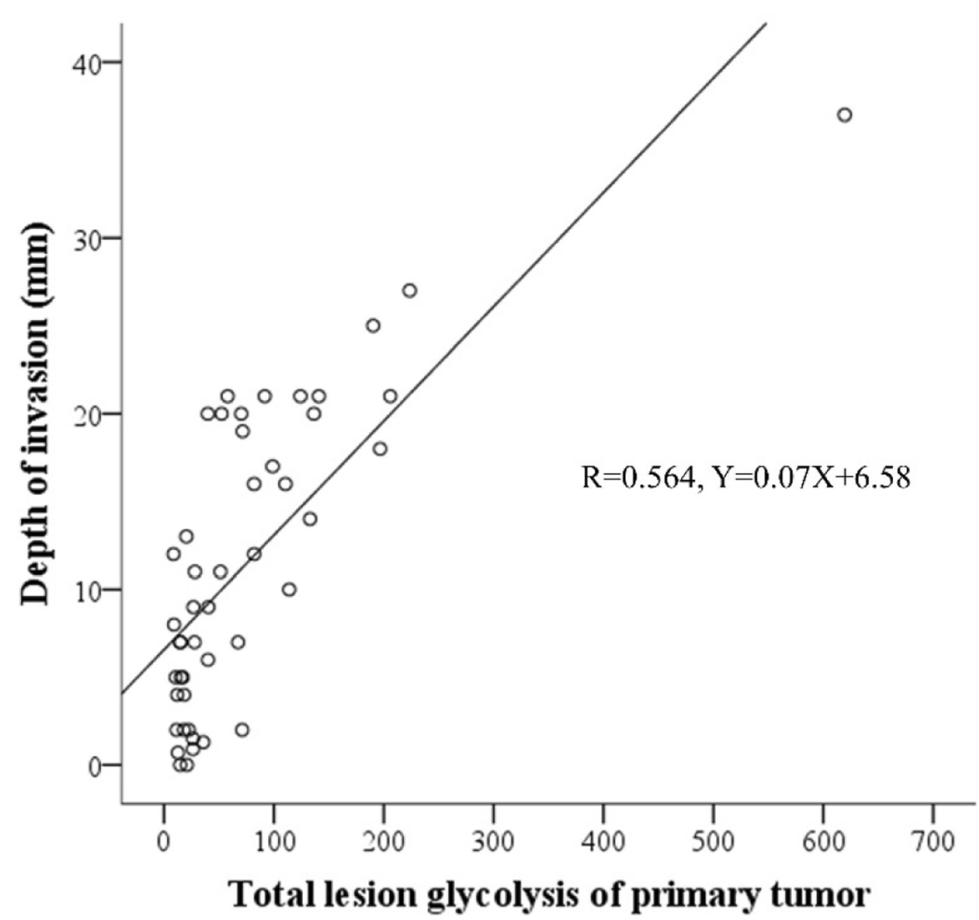

Fig. 3 Correlation between the depth of invasion and volume-based parameters (a: T-MTV, b: T-TLG) of the primary tumors. Volume-based parameters, such as T-MTV and T-TLG in PET-CT as functional images, were useful for T-staging to determine the tumor extent. T-MTV = metabolic tumor volume of primary tumor, T-TLG = total lesion glycolysis of primary tumor 
A

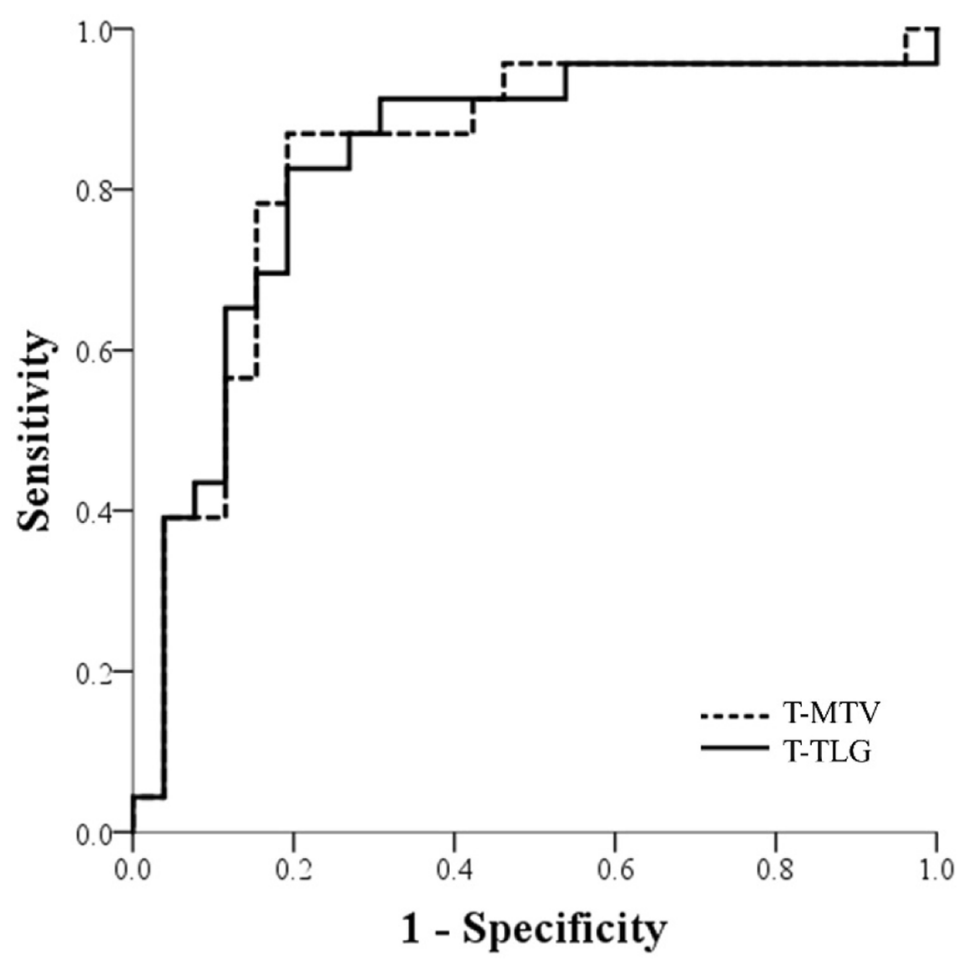

B

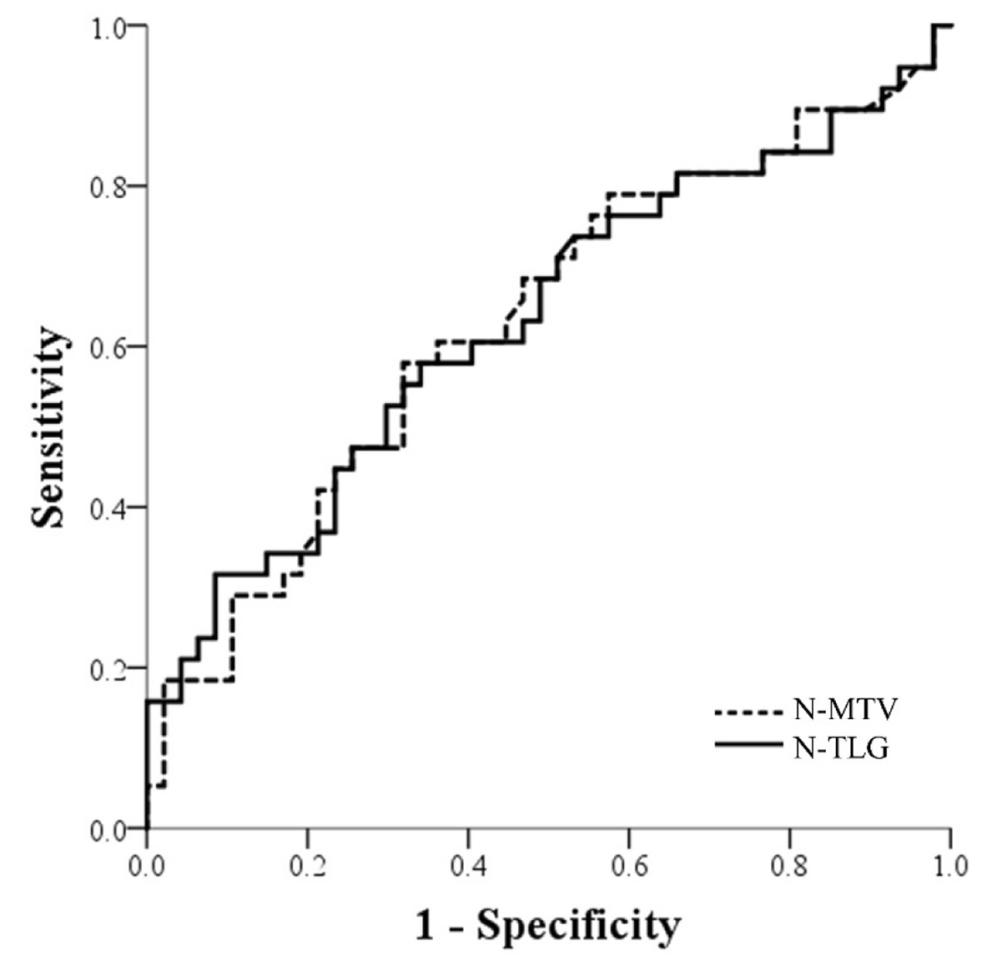

Fig. 4 Receiver operating characteristic curve predicting (a) depth of invasion (>10 $\mathrm{mm}$ ) in the primary tumor for metabolic tumor volume and total lesion glycolysis and (b) extranodal extension for nodal total lesion glycolysis. T-MTV = metabolic tumor volume of primary tumor, T-TLG $=$ total lesion glycolysis of primary tumor, N-MTV = metabolic tumor volume of metastatic node, N-TLG = total lesion glycolysis of metastatic node 
Table 2 Univariate and multivariate logistic regression analyses of DOI of primary lesion (A) and ENE of metastatic nodes (B)

\begin{tabular}{|c|c|c|c|}
\hline & UVA & MVA & OR $(95 \% \mathrm{Cl})$ \\
\hline \multicolumn{4}{|l|}{ (A) } \\
\hline T-Max ( $\leq 10$ vs. $>10)$ & 0.003 & 0.691 & \\
\hline T-MTV $\left(\leq 15 \mathrm{~cm}^{3}\right.$ vs. $\left.>15 \mathrm{~cm}^{3}\right)$ & 0.003 & 0.348 & \\
\hline T-TLG $\left(\leq 70 \mathrm{~cm}^{3}\right.$ vs. $\left.>70 \mathrm{~cm}^{3}\right)$ & $<0.001$ & $<0.001$ & $13.143(3.292-52.466)$ \\
\hline HPV (positive vs. negative) & 0.627 & & \\
\hline Ki-67 ( $\leq 70 \%$ vs. $>70 \%)$ & 0.197 & & \\
\hline Lymphovascular invasion (yes vs. no) & 0.206 & & \\
\hline Perineural invasion (yes vs. no) & 0.999 & & \\
\hline Tumor grade (well vs. moderate vs. poor) & 0.405 & & \\
\hline \multicolumn{4}{|l|}{ (B) } \\
\hline $\mathrm{N}-\operatorname{Max}(\leq 11$ vs. $>11)$ & 0.021 & 0.132 & \\
\hline $\operatorname{N-MTV}\left(\leq 4 \mathrm{~cm}^{3}\right.$ vs. $\left.>4 \mathrm{~cm}^{3}\right)$ & 0.018 & 0.016 & $2.933(1.205-7.138)$ \\
\hline N-TLG $\left(\leq 15 \mathrm{~cm}^{3}\right.$ vs. $\left.>15 \mathrm{~cm}^{3}\right)$ & 0.330 & & \\
\hline HPV (positive vs. negative) & 0.081 & & \\
\hline Ki-67 ( $\leq 70 \%$ vs. $>70 \%)$ & 0.229 & & \\
\hline Lymphovascular invasion (yes vs. no) & 0.330 & & \\
\hline
\end{tabular}

Abbreviation: DOI depth of invasion, ENE extranodal extension, T-Max maximum standardized uptake value of primary tumor, $T$-MTV metabolic tumor volume of $\mathrm{T}$, T-TLG total lesion glycolysis of T, HPV human papillomavirus, UVA univariate analysis, MVA multivariate analysis, OR odds ratio, $\mathrm{Cl}$ confidence interval, N-Max maximum standardized uptake value of metastatic node, N-MTV metabolic tumor volume of metastatic node, N-TLG total lesion glycolysis of metastatic node

and the DOI of oropharyngeal cancer, including tonsils, were correlated. Among them, TLG was a strong factor affecting the DOI of primary tumors. This demonstrated that higher primary tumor TLG meant a deeper depth of invasion and suggests that tumor invasion depth could be represented by volumetric functional imaging rather than by anatomic imaging such as CT or MRI alone in oropharyngeal cancer.

In addition, there are few studies of radiologic factors related to ENE, which are important factors in the prognosis of oropharyngeal cancer. A recent study divided the risk groups based on nodal MTV and ENE in laryngeal and hypopharyngeal cancers to explain the significant differences in survival analysis. Fujii et al. [26] analyzed the nodal MTV in PET-CT as a factor influencing the OS of patients with stage III/IV laryngeal or hypopharyngeal cancer who were treated with surgery, which showed stronger prognostic power than ENE. In the current study, additionally, the metastatic lymph nodes of oropharyngeal cancer were matched with the surgical pathologic findings, and the results showed that N-MTV was significantly associated with ENE in oropharyngeal cancer.

Recently, several studies on the de-intensification of treatment for HPV-positive oropharyngeal cancer have been actively conducted [27-29]. Previous studies analyzed the prognostic value of volumetric PET parameters associated with event-free survival in HPV-positive oropharyngeal cancer patients $[18,24,30]$. Chotchutipan et al. evaluated volumetric PET parameters in low-risk
HPV-positive OPC patients treated with definitive chemoradiation, and analyzed the data to be prognostic of locoregional failure-free survival. The clinical stage was found to be a potent factor affecting distant metastasisfree survival or OS [30]. However, there has been no study to determine whether PET parameters associated with HPV positivity in oropharyngeal cancer. In the current study, there was no relationship between PET parameters and HPV infection, suggesting the limitation of PET as a useful tool for changes or de-intensification of treatment according to HPV status.

\section{Conclusion}

In conclusion, volumetric parameters in PET were associated with survival, recurrence, invasion depth, and extranodal extension in oropharyngeal cancer. More evidence is needed before these findings are applied to the postoperative adjuvant treatment strategy for resected OPC patients. Further long-term follow-up assessments and prospective studies with large number of patients will be indicated in the near future.

\section{Abbreviations}

PET: Positron-emission tomography; ${ }^{18}$ F-FDG: ${ }^{18}$ F-fluorodeoxyglucose; CT: Computed tomography; SUV: Standardized uptake values;

ENE: Extranodal extension; LN: Lymph node; DOI: Depth of invasion; HPV: Human papillomavirus; ROI: Region-of-interest; SUVmax: Maximum SUV; MTV: Metabolic tumor volume; TLG: Total lesion glycolysis; TLR: Ratio of the tumor-to-liver SUV; VOI: Volume of interest; ROC: Receiver operating characteristic; OS: Overall survival; RFS: Recurrence-free survival; T: Primary tumor; N: Metastatic node; $\mathrm{tN}$ : Total metastatic nodes; AUC: Area under the curve; $\mathrm{Cl}$ : Confidence interval 


\section{Acknowledgements}

None.

\section{Authors' contributions}

All authors made substantial contributions to one or more of the following: the study conception and design: $\mathrm{KHC}$, JHS and Y-SK; provision of study materials or patients: KHC, D-IL, M-SK and Y-SK; collection and assembly of data: KHC, EYP and JHH; data analysis and interpretation: KHC, JHS, IRY, YSL and YSK; KHC, JHS and Y-SK drafted the article. KHC and Y-SK contributed to revising the article critically for important intellectual content. All authors read and approved the final manuscript.

\section{Funding}

Not applicable.

\section{Availability of data and materials}

The dataset of the current study was available from the corresponding author on reasonable request.

\section{Declarations}

\section{Ethics approval and consent to participate}

The Institutional Review Board of the Catholic Medical Center, the Catholic University of Korea approved the study protocol (No. KC19RISI0812). Informed consent was waived due to the retrospective study design by the same ethics committee that approved this study (The Institutional Review Board of the Catholic Medical Center, the Catholic University of Korea).

\section{Consent for publication}

Not applicable.

\section{Competing interests}

The authors declare that they have no conflict of interest.

\begin{abstract}
Author details
'Department of Radiation Oncology, Seoul St. Mary's Hospital, College of Medicine, The Catholic University of Korea, Seoul, Republic of Korea. ${ }^{2}$ Department of Nuclear Medicine, Seoul St. Mary's Hospital, College of Medicine, The Catholic University of Korea, Seoul, Republic of Korea. ${ }^{3}$ Department of Pathology, Seoul St. Mary's Hospital, College of Medicine, The Catholic University of Korea, Seoul, Republic of Korea. ${ }^{4}$ Department of Otorhinolaryngology, Seoul St. Mary's Hospital, College of Medicine, The Catholic University of Korea, Seoul, Republic of Korea.
\end{abstract}

Received: 15 January 2021 Accepted: 8 March 2021

Published online: 25 March 2021

\section{References}

1. Strauss LG, Conti PS. The applications of PET in clinical oncology. J Nucl Med. 1991:32(4):623-48.

2. Bai B, Bading J, Conti PS. Tumor quantification in clinical positron emission tomography. Theranostics. 2013;3(10):787-801. https://doi.org/1 $0.7150 /$ thno.5629

3. Larson SM, Erdi Y, Akhurst T, Mazumdar M, Macapinlac HA, Finn RD, Casilla C, Fazzari M, Srivastava N, Yeung HW, Humm JL, Guillem J, Downey R, Karpeh M, Cohen AE, Ginsberg R. Tumor treatment response based on visual and quantitative changes in global tumor glycolysis using PET-FDG imaging. The visual response score and the change in Total lesion glycolysis. Clin Positron Imaging. 1999;2(3):159-71. https://doi.org/10.1016/ S1095-0397(99)00016-3.

4. Downey RJ, Akhurst T, Gonen M, Vincent A, Bains MS, Larson S, Rusch V. Preoperative F-18 fluorodeoxyglucose-positron emission tomography maximal standardized uptake value predicts survival after lung cancer resection. J Clin Oncol. 2004;22(16):3255-60. https://doi.org/10.1200/ JCO.2004.11.109.

5. Kidd EA, Siegel BA, Dehdashti F, Grigsby PW. The standardized uptake value for F-18 fluorodeoxyglucose is a sensitive predictive biomarker for cervical cancer treatment response and survival. Cancer. 2007;110(8):1738-44. https://doi.org/10.1002/cncr.22974.

6. Machtay M, Natwa M, Andrel J, Hyslop T, Anne PR, Lavarino J, Intenzo CM, Keane W. Pretreatment FDG-PET standardized uptake value as a prognostic factor for outcome in head and neck cancer. Head Neck. 2009;31(2):195201. https://doi.org/10.1002/hed.20942.

7. Higgins KA, Hoang JK, Roach MC, Chino J, Yoo DS, Turkington TG, Brizel DM. Analysis of pretreatment FDG-PET SUV parameters in head-and-neck cancer: tumor SUVmean has superior prognostic value. Int J Radiat Oncol Biol Phys. 2012;82(2):548-53. https://doi.org/10.1016/j.jjrobp.2010.11.050.

8. Moon SH, Hyun SH, Choi JY. Prognostic significance of volume-based PET parameters in cancer patients. Korean J Radiol. 2013;14(1):1-12. https://doi. org/10.3348/kjr.2013.14.1.1.

9. Myers JN, Greenberg JS, Mo V, Roberts D. Extracapsular spread. A significant predictor of treatment failure in patients with squamous cell carcinoma of the tongue. Cancer. 2001;92(12):3030-6. https://doi.org/10.1002/1097-0142 (20011215)92:12<3030::AID-CNCR10148>3.0.CO;2-P.

10. Ferlito A, Rinaldo A, Devaney KO, MacLennan K, Myers JN, Petruzzelli GJ, Shaha AR, Genden EM, Johnson JT, de Carvalho MB, Myers EN. Prognostic significance of microscopic and macroscopic extracapsular spread from metastatic tumor in the cervical lymph nodes. Oral Oncol. 2002;38(8):74751. https://doi.org/10.1016/\$1368-8375(02)00052-0.

11. Huang SH, O'Sullivan B. Overview of the 8th edition TNM classification for head and neck Cancer. Curr Treat Options in Oncol. 2017;18(7):40. https:// doi.org/10.1007/s11864-017-0484-y.

12. Ravasz LA, Slootweg PJ, Hordijk GJ, Smit F, van der Tweel I. The status of the resection margin as a prognostic factor in the treatment of head and neck carcinoma. J Craniomaxillofac Surg. 1991;19(7):314-8. https://doi.org/1 0.1016/S1010-5182(05)80339-7.

13. Bradley PJ, MacLennan K, Brakenhoff RH, Leemans CR. Status of primary tumour surgical margins in squamous head and neck cancer: prognostic implications. Curr Opin Otolaryngol Head Neck Surg. 2007;15(2):74-81. https://doi.org/10.1097/MO0.0b013e328058670f.

14. O'Sullivan B, Huang SH, Su J, Garden AS, Sturgis EM, Dahlstrom K, Lee N, Riaz N, Pei X, Koyfman SA, Adelstein D, Burkey BB, Friborg J, Kristensen CA, Gothelf AB, Hoebers F, Kremer B, Speel EJ, Bowles DW, Raben D, Karam SD, Yu E, Xu W. Development and validation of a staging system for HPVrelated oropharyngeal cancer by the international collaboration on Oropharyngeal cancer network for staging (ICON-S): a multicentre cohort study. Lancet Oncol. 2016;17(4):440-51. https://doi.org/10.1016/S1470-204 5(15)00560-4

15. Haughey BH, Sinha P, Kallogjeri D, Goldberg RL, Lewis JS Jr, Piccirillo JF, Jackson RS, Moore EJ, Brandwein-Gensler M, Magnuson SJ, Carroll WR, Jones TM, Wilkie MD, Lau A, Upile NS, Sheard J, Lancaster J, Tandon S, Robinson M, Husband D, Ganly I, Shah JP, Brizel DM, O'Sullivan B, Ridge JA, Lydiatt WM. Pathology-based staging for HPV-positive squamous carcinoma of the oropharynx. Oral Oncol. 2016;62:11-9. https://doi.org/10.1016/j.ora loncology.2016.09.004.

16. Annunziata S, Cuccaro A, Calcagni ML, Hohaus S, Giordano A, Rufini V. Interim FDG-PET/CT in Hodgkin lymphoma: the prognostic role of the ratio between target lesion and liver SUVmax (rPET). Ann Nucl Med. 2016;30(8): 588-92. https://doi.org/10.1007/s12149-016-1092-9.

17. Annunziata S, Cuccaro A, Tisi MC, Hohaus S, Rufini V. FDG-PET/CT at the end of immuno-chemotherapy in follicular lymphoma: the prognostic role of the ratio between target lesion and liver SUV(max) (rPET). Ann Nucl Med. 2018;32(5):372-7. https://doi.org/10.1007/s12149-018-1243-2.

18. Porceddu SV, Pryor DI, Burmeister E, Burmeister BH, Poulsen MG, Foote MC, Panizza B, Coman S, McFarlane D, Coman W. Results of a prospective study of positron emission tomography-directed management of residual nodal abnormalities in node-positive head and neck cancer after definitive radiotherapy with or without systemic therapy. Head Neck. 2011;33(12): 1675-82. https://doi.org/10.1002/hed.21655.

19. Tang C, Murphy JD, Khong B, La TH, Kong C, Fischbein NJ, Colevas AD, lagaru AH, Graves EE, Loo BW Jr, et al. Validation that metabolic tumor volume predicts outcome in head-and-neck cancer. Int J Radiat Oncol Biol Phys. 2012;83(5):1514-20. https://doi.org/10.1016/j.jijobp.2011.10.023.

20. La TH, Filion EJ, Turnbull BB, Chu JN, Lee P, Nguyen K, Maxim P, Quon A, Graves EE, Loo BW Jr, et al. Metabolic tumor volume predicts for recurrence and death in head-and-neck cancer. Int J Radiat Oncol Biol Phys. 2009;74(5): 1335-41. https://doi.org/10.1016/j.jjrobp.2008.10.060.

21. Choi KH, Yoo le R, Han EJ, Kim YS, Kim GW, Na SJ, Sun DI, Jung SL, Jung CK, Kim MS, et al. Prognostic value of metabolic tumor volume measured by (18)F-FDG PET/CT in locally advanced head and neck squamous cell carcinomas treated by surgery. Nucl Med Mol Imaging. 2011;45(1):43-51. https://doi.org/10.1007/s13139-010-0063-7. 
22. Hsieh H-Y, Liu Y-C, Lin J-W, Lin J-C: Prognostic effects of the metabolic tumor volume and total lesion glycolysis in patients with advanced squamous cell carcinoma of head and neck. Ther Radiol Oncol. 2018;2(5):19. http://dx.doi.org/10.21037/tro.2018.01.08.

23. Kim S, Oh S, Kim JS, Kim YK, Kim KH, Oh DH, Lee DH, Jeong WJ, Jung YH. Prognostic value of FDG PET/CT during radiotherapy in head and neck cancer patients. Radiat Oncol J. 2018;36(2):95-102. https://doi.org/10.3857/ roj.2017.00577.

24. Alluri KC, Tahari AK, Wahl RL, Koch W, Chung CH, Subramaniam RM. Prognostic value of FDG PET metabolic tumor volume in human papillomavirus-positive stage III and IV oropharyngeal squamous cell carcinoma. Am J Roentgenol. 2014;203(4):897-903. https://doi.org/10.2214/A JR.14.12497.

25. Park JO, Jung SL, Joo YH, Jung CK, Cho KJ, Kim MS. Diagnostic accuracy of magnetic resonance imaging (MRI) in the assessment of tumor invasion depth in oral/oropharyngeal cancer. Oral Oncol. 2011;47(5):381-6. https:// doi.org/10.1016/j.oraloncology.2011.03.012.

26. Fujii T, Miyabe J, Yoshii T, Suzuki M, Otozai S, Komukai S, Kishikawa T, Takemoto N, Fukusumi T, Tatsumi M, Hatazawa J, Inohara H. Metabolic tumor volume of metastatic lymph nodes and survival after total laryngectomy in laryngeal and hypopharyngeal cancer. Oral Oncol. 2019;93: 107-13. https://doi.org/10.1016/j.oraloncology.2019.04.011.

27. O'Sullivan B, Huang SH, Siu LL, Waldron J, Zhao H, Perez-Ordonez B, Weinreb I, Kim J, Ringash J, Bayley A, Dawson LA, Hope A, Cho J, Irish J, Gilbert R, Gullane P, Hui A, Liu FF, Chen E, Xu W. Deintensification candidate subgroups in human papillomavirus-related oropharyngeal cancer according to minimal risk of distant metastasis. J Clin Oncol. 2013;31(5):54350. https://doi.org/10.1200/JCO.2012.44.0164.

28. Quon H, Forastiere AA. Controversies in treatment deintensification of human papillomavirus-associated oropharyngeal carcinomas: should we, how should we, and for whom? J Clin Oncol. 2013;31(5):520-2. https://doi. org/10.1200/JCO.2012.46.7746.

29. Masterson L, Moualed D, Masood A, Dwivedi RC, Benson R, Sterling JC, Rhodes KM, Sudhoff H, Jani P, Goon P: De-escalation treatment protocols for human papillomavirus-associated oropharyngeal squamous cell carcinoma. Cochrane Database Syst Rev. 2014;1 (2):Cd010271. https://doi. org/10.1002/14651858.CD010271.pub2.

30. Chotchutipan T, Rosen BS, Hawkins PG, Lee JY, Saripalli AL, Thakkar D, Eisbruch A, El Naqa I, Mierzwa ML. Volumetric (18) F-FDG-PET parameters as predictors of locoregional failure in low-risk HPV-related oropharyngeal cancer after definitive chemoradiation therapy. Head Neck. 2019;41(2):366-73. https://doi.org/10.1002/hed.25505.

\section{Publisher's Note}

Springer Nature remains neutral with regard to jurisdictional claims in published maps and institutional affiliations.

Ready to submit your research? Choose BMC and benefit from:

- fast, convenient online submission

- thorough peer review by experienced researchers in your field

- rapid publication on acceptance

- support for research data, including large and complex data types

- gold Open Access which fosters wider collaboration and increased citations

- maximum visibility for your research: over $100 \mathrm{M}$ website views per year

At BMC, research is always in progress.

Learn more biomedcentral.com/submissions 